\title{
Diet, Food Insecurity, and CVD Risk in Sexual and Gender Minority Adults
}

\author{
Billy A. Caceres ${ }^{1}$ (D) Melissa Bynon ${ }^{1} \cdot$ Danny Doan ${ }^{1} \cdot$ Nour Makarem $^{2} \cdot$ Amanda C. McClain $^{3} \cdot$ Nicole VanKim $^{4}$
}

Accepted: 22 October 2021 / Published online: 2 February 2022

(c) The Author(s), under exclusive licence to Springer Science+Business Media, LLC, part of Springer Nature 2022

\begin{abstract}
Purpose of Review Sexual and gender minority (SGM) adults experience significant cardiovascular health disparities, yet little is known about diet and food insecurity in this population. This review summarizes recent literature on diet and food insecurity in SGM adults and their contribution to cardiovascular disease (CVD) risk in this population.

Recent Findings Existing evidence on diet and food insecurity disparities among SGM adults is inconclusive and research examining their link with CVD risk in SGM adults is limited. The majority of existing studies lack standardized and validated assessments of diet and food insecurity. Correlates of unhealthy diet and food insecurity among SGM adults are poorly understood.

Summary Research examining the associations between diet and food insecurity with CVD risk in SGM adults is limited. Longitudinal studies are needed to investigate whether diet and food insecurity contribute to the cardiovascular health disparities observed in SGM adults.
\end{abstract}

Keywords Sexual and gender minorities · Diet · Nutrition · Food insecurity · Cardiovascular disease

Billy A. Caceres

bac2134@cumc.columbia.edu

Melissa Bynon

mb4758@cumc.columbia.edu

Danny Doan

dv2439@cumc.columbia.edu

Nour Makarem

nm2968@cumc.columbia.edu

Amanda C. McClain

amcclain@sdsu.edu

Nicole VanKim

nvankim@umass.edu

1 Columbia University School of Nursing, 560 West 168th Street, New York, NY 10032, USA

2 Mailman School of Public Health, Columbia University Irving Medical Center, New York, NY, USA

3 School of Exercise and Nutritional Sciences, San Diego State University, San Diego, CA, USA

4 University of Massachusetts-Amherst School of Public Health and Health Sciences, Amherst, MA, USA

\section{Introduction}

Sexual and gender minority (SGM) adults experience significant cardiovascular health $(\mathrm{CVH})$ disparities related to greater exposure to marginalization and discrimination [1]. Table 1 describes terms relevant to SGM health that are used in this review. Growing evidence demonstrates that SGM adults are at higher risk for cardiovascular diseases (CVD)

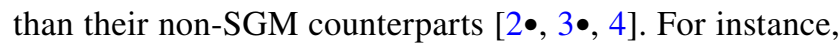
lesbian and bisexual women have a higher prevalence of tobacco use, obesity, and hyperglycemia than heterosexual women [5-8]. Bisexual men are two to three times more likely than heterosexual men to meet criteria for obesity and type 2 diabetes [9]. Also, a recent meta-analysis of 20 studies found that bisexual men were two times more likely than heterosexual men to have hypertension [10]. Compared to cisgender men and women (i.e., individuals whose gender identity is aligned with their sex assigned at birth), transgender women are two to three times more likely to have been diagnosed with a heart attack or ischemic stroke [11-14]. However, evidence of CVH disparities among transgender men is conflicting $[13,15]$.

Much of the risk for CVD in SGM adults is attributed to psychosocial, clinical, and behavioral factors. The minority 
Table 1 Terms relevant to sexual and gender minority health

\begin{tabular}{|c|c|}
\hline \multicolumn{2}{|c|}{ Terms relating to sexual orientation } \\
\hline $\begin{array}{l}\text { Sexual orientation } \\
\text { (noun) }\end{array}$ & $\begin{array}{l}\text { Refers to how a person characterizes their physical, emotional, or romantic attachments in relation to } \\
\text { gender. Separate from gender identity. Can be defined based on sexual identity, sexual behavior, and/or } \\
\text { sexual attraction }\end{array}$ \\
\hline $\begin{array}{l}\text { Sexual minority } \\
\text { (noun) }\end{array}$ & $\begin{array}{l}\text { Refers to individuals who have a sexual orientation that is anything other than heterosexual. Can include } \\
\text { lesbian, gay, bisexual, or queer individuals as well as persons with other sexual orientations }\end{array}$ \\
\hline $\begin{array}{l}\text { Queer } \\
\text { (adjective) }\end{array}$ & $\begin{array}{l}\text { Queer is frequently used as an umbrella term to represent all individuals who identify outside traditional } \\
\text { categories for sexual orientation and gender identity. Historically a derogatory term used against sexual } \\
\text { and gender minority individuals. It has been reclaimed by many sexual and gender minority individuals } \\
\text { as a term of empowerment }\end{array}$ \\
\hline $\begin{array}{l}\text { Heterosexual } \\
\text { (adjective) }\end{array}$ & $\begin{array}{l}\text { Refers to individuals who are attracted to people of a gender different than their own. Often used inter- } \\
\text { changeably with "straight." Cisgender and transgender individuals may identify as heterosexual }\end{array}$ \\
\hline \multicolumn{2}{|c|}{ Terms relating to sex and gender } \\
\hline $\begin{array}{l}\text { Sex } \\
\text { (noun) }\end{array}$ & $\begin{array}{l}\text { Refers to biological and anatomical sex characteristics (including chromosomes, gonads, sex hormones, } \\
\text { and/or genitals). Categories include male, female, and intersex. Often used interchangeably with "sex } \\
\text { assigned at birth" or "biological sex." }\end{array}$ \\
\hline $\begin{array}{l}\text { Sex assigned at birth } \\
\text { (noun) }\end{array}$ & $\begin{array}{l}\text { Used to describe an infant based on their external anatomy and typically categorized as male or female; } \\
\text { different from gender identity }\end{array}$ \\
\hline $\begin{array}{l}\text { Gender identity } \\
\text { (noun) }\end{array}$ & $\begin{array}{l}\text { Refers to a person's inner sense of being a boy/man, a girl/woman, a combination of boy/man and girl/ } \\
\text { woman, having no gender at all, or something else }\end{array}$ \\
\hline $\begin{array}{l}\text { Gender minority } \\
\text { (noun) }\end{array}$ & $\begin{array}{l}\text { Refers to individuals who experience an incongruence between their gender identity and what is typically } \\
\text { expected based on their sex assigned at birth. Can include transgender, gender non-binary persons, } \\
\text { intersex, and other gender diverse persons }\end{array}$ \\
\hline $\begin{array}{l}\text { Cisgender } \\
\text { (adjective) }\end{array}$ & $\begin{array}{l}\text { A gender identity used to describe people whose gender identity is consistent with societal expectations } \\
\text { based on their sex assigned at birth. A female-identified person who was assigned female sex at birth } \\
\text { would be considered a cisgender female or woman }\end{array}$ \\
\hline $\begin{array}{l}\text { Gender non-binary } \\
\text { (adjective) }\end{array}$ & $\begin{array}{l}\text { A term used by people who identify outside the typical expectations of the gender binary. This term is } \\
\text { often used interchangeably with "gender non-conforming," which is considered more outdated }\end{array}$ \\
\hline
\end{tabular}

stress model, the prevailing framework for understanding SGM health disparities $[16,17]$, posits that SGM individuals experience unique psychosocial stressors, called minority stressors, related to their marginalized status in society [16, 17]. These minority stressors can exist at the individual (e.g., expectations of rejection), interpersonal (e.g., experiences of discrimination), and structural (e.g., anti-SGM legislation) levels $[2 \bullet, 3 \bullet]$. With few exceptions, there has been limited research examining the link between minority stressors and

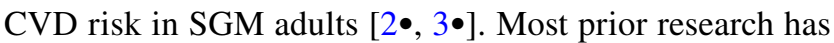
focused on the relationships between minority stressors and tobacco use in SGM adults [18-20]. Another factor posited to contribute to CVD risk in gender minority adults is the use of gender-affirming hormones (e.g., estrogen, testosterone), which are used to acquire secondary sex characteristics that are more aligned with one's gender identity [2•, 13, 15]. More than $50 \%$ of transgender adults report using genderaffirming hormones [21, 22]. Evidence of the cardiovascular effects of gender-affirming hormones is largely mixed [2•, $13,15,20]$. However, in a recent cohort study of $>100,000$ adults (5\% transgender), Getahun et al. [11] found that use of estrogen during 8-year follow-up was associated with an increased incidence of stroke among transgender women, relative to cisgender women.
Behavioral factors are hypothesized to play a role in CVD risk among SGM adults. Although disparities in tobacco use and physical inactivity have been documented among SGM adults $[2 \bullet, 3 \bullet, 23]$, research on diet in this population remains limited. Diet is an important predictor of CVD risk and a key metric of CVH [24-27]. In fact, analyses of data from the Global Burden of Disease Study found that diet was the top modifiable risk factor for CVD mortality, accounting for $\sim 70 \%$ of CVD-related deaths worldwide between 1990 and 2017 [28]. Multiple systematic reviews and metaanalyses have found that increased intake of certain dietary components (e.g., whole grains, fish, fruits, vegetables, and plant-based proteins) is associated with lower cardiovascular and all-cause mortality among adults [29-32]. Despite slight improvements in diet quality among adults in the general population over the past two decades, diet quality is the $\mathrm{CVH}$ metric that is the least likely to meet recommended criteria [33-36].

Food insecurity, defined as the lack of "consistent, dependable access to enough food for active, healthy living [37]," is a recognized social determinant of poor diet quality [38, 39]. Food insecurity is a highly prevalent public health concern. In 2019, an estimated one in ten people were exposed to severe food insecurity worldwide [40]. Further, findings from systematic reviews indicate that 
food insecurity is associated with a higher risk for incident hypertension, type 2 diabetes, and CVD, as well as greater cardiovascular mortality [41-45]. Certain groups of SGM adults, including lesbian women and bisexual and transgender adults, have higher rates of poverty compared to their non-SGM counterparts, which may increase their risk for food insecurity [46, 47]. In addition, food insecurity is strongly linked with exposure to violence [48], which is more prevalent among SGM adults relative to non-SGM adults [49-51]. Yet, studies on food insecurity among SGM adults are limited.

Although there is growing evidence that SGM adults have a higher prevalence of CVD risk factors than their non-SGM counterparts $[2 \bullet, 3 \bullet]$, to date, no review has examined the influence of diet and food insecurity on CVD risk in SGM adults (ages 18 and over). The purpose of this review was to summarize recent literature related to diet and food insecurity in SGM adults and their contribution to CVD risk in this population. For the purposes of this review, we defined diet broadly to include measures of diet quality, meal patterns, eating behaviors, nutritional intake, and food choice behaviors. Similarly, for food insecurity, we included studies that measured food insecurity or food insufficiency. We did not include studies that reported on disordered eating or body image concerns in SGM adults as these topics have been comprehensively reviewed in prior reviews [52-54].

\section{Diet in SGM Adults}

We summarize findings for studies that investigated some component of diet among SGM adults (Supplemental Table 1). The majority of these studies were cross-sectional $(n=14)$, except for three longitudinal analyses of data from the Nurses' Health Study and the Growing Up Today Study $[55,56 \bullet \bullet, 57 \bullet \bullet]$. All but one of these studies was conducted in the United States (U.S.).

\section{Sexual Minority Adults}

Findings from research examining diet among sexual minority adults are largely conflicting. Analyses of data from the College Student Health Survey [58] showed significant differences in meal patterns between sexual minority and heterosexual college students. Breakfast consumption was assessed by asking participants: "In the past 7 days, how many days did you eat breakfast?" Responses were categorized as 0-1 days per week, 2-4 days per week, or 5-7 days per week. Compared to heterosexual women, bisexual women were more likely to eat breakfast on only $0-1$ days per week ( $17.3 \%$ vs. $12.2 \%, p=0.004)$. In contrast, bisexual women were less likely than heterosexual women to report consuming fast foods several times per week (50.8\% vs.
$59.4 \%, p<0.001)$. Fruit/vegetable or soda consumption did not differ by sexual identity among women or men. Similarly, two studies using data from the National Health and Nutrition Examination Survey (NHANES) (2001-2012) found no significant differences in dietary fat intake (i.e., ratio of unsaturated to saturated fat derived from the Healthy Eating Index-2010) between sexual minority and heterosexual adults of the same sex [7,9].

In analyses of data from the Nurses' Health Study II, VanKim et al. [55] found significant differences in validated measures of diet quality between sexual minority and heterosexual women. Both lesbian and bisexual women had higher Alternative Health Eating Index (AHEI) and Dietary Approaches to Stop Hypertension (DASH) scores than heterosexual women, indicating better diet quality. Lesbian women reported lower total fat intake and lower dietary glycemic index (i.e., a measure of how quickly carbohydratecontaining foods raise blood sugar levels). Differences in diet quality between bisexual and heterosexual women were mixed. Compared to heterosexual women, bisexual women had diets with higher fiber intake and which were lower on the glycemic index. In contrast, bisexual women reported consuming more calories per day than heterosexual women. Sexual identity differences in AHEI scores were more pronounced among women over the age of 50 [55]. Consistent with these findings, data from the Nurses' Health Study 3 revealed that women who identified as lesbian or "mostly lesbian" had higher DASH and American Heart Association diet scores than exclusively heterosexual women, indicating

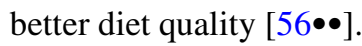

Similar trends between sexual minority and heterosexual women were documented in the Growing Up Today Study $[57 \bullet \bullet]$. Compared to exclusively heterosexual female participants, women who identified as "mostly heterosexual" or bisexual were more likely to report regularly consuming breakfast on five or more days each week. "Mostly heterosexual" women also had higher AHEI scores compared to exclusively heterosexual women $(B=0.70,95 \%$ $\mathrm{CI}=0.10-1.3, p<0.05)$.

On the other hand, additional studies found lesbian and bisexual women had lower or no difference in diet compared to heterosexual women. Minnis and colleagues [59] found that sexual minority women reported higher odds of consuming sugar-sweetened beverages in the past week than heterosexual women. Compared to heterosexual women, lesbian women also reported lower daily vegetable consumption [59]. In analyses of data from the Epidemiologic Study of Risk in Women $(N=867)$, Caceres et al. [49] found no difference in the number of times that sexual minority and heterosexual women ate fast food in a usual week $(p=0.96)$, which contradicts findings from Laska and colleagues [58].

We identified fewer studies that focused on diet among sexual minority men, but findings were also mixed. The 
aforementioned analyses of the Growing Up Today Study indicated no differences in AHEI scores by sexual identity

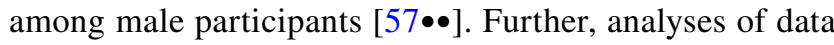
from the 2013-2014 Adult Targeted Surveillance Survey found that gay men were more likely than heterosexual men to consume meals prepared away from home and sugarsweetened beverages in the past week [59]. Bisexual men reported higher daily fruit consumption than heterosexual men [59].

\section{Gender Minority Adults}

Only four studies examined diet in gender minority adults [57••, 60-62]. In an online cross-sectional study of over 3000 adults ( $9.9 \%$ gender minority), investigators found that transgender women were less likely than cisgender women to eat $\geq 5$ servings/day of fruit $(21.1 \%$ vs. $39.6 \%, p<0.05)$. Compared to cisgender men (25.5\%) and cisgender women (34.6\%), transgender women (11.3\%) were also less likely to eat $\geq 3$ servings/day of vegetables [62]. Using longitudinal data from the Growing Up Today Study, investigators examined gender expression (i.e., very gender-conforming, mostly gender-conforming, gender non-conforming) differences in diet quality scores and eating habits among young adults [57••]. Male-identified participants who were mostly gender-conforming had higher AHEI scores compared to very gender-conforming participants of the same sex, but AHEI scores did not differ by gender expression among femaleidentified participants. Similarly, breakfast consumption did not differ by gender expression among male-identified participants, but gender non-conforming females were less likely to consume breakfast than very gender-conforming females [57••]. In one of the few studies conducted outside of the U.S., investigators found that in a community sample of 200 transgender adults living in India, the majority reported consuming less than the recommended five servings of fruits and/or vegetables per day (90.5\%) [61].

\section{Correlates of Diet in SGM Adults}

Only three studies reported on correlates of diet among SGM adults [60, 63, 64]. In an online sample of 670 SGM adults, investigators [63] found that $>70 \%$ of participants reported diets high in saturated fat or sodium. In addition, higher report of distal minority stressors (such as harassment and discrimination) was associated with higher odds of reporting a diet high in saturated fat or sodium among men only [63]. A notable limitation of the study was the use of a single dichotomous measure to assess if participants had diets high in both saturated fats and sodium [63]. Therefore, it is unknown whether minority stressors were more strongly associated with either saturated fat or sodium intake. Further, in a qualitative study of sexual minority college students $(N=30)$, investigators explored participants' perceptions about sexual orientation-related barriers to healthy eating [64]. Responses were mixed, with approximately half of participants reporting they felt that their sexual orientation did not influence their decisions around eating. Other participants felt that being more connected to the SGM community promoted healthy eating habits [64]. In addition, a mixed-methods study conducted to assess barriers to health and nutrition among gender minority college students $(N=26)$ [60] found that $<50 \%$ of participants ate fruit or vegetables daily during the past seven days, and $>55 \%$ did not eat whole grains in the past week. Several barriers to eating more fruits and vegetables were identified, including limited access to cooking spaces, lack of transportation to affordable grocery stores, and increased cost of fresh foods [60].

\section{Diet and CVD Risk in SGM Adults}

There is limited research examining diet as a predictor of CVD risk in SGM adults and findings are largely null [7, 9, 65-67]. All of these studies were focused on sexual minority populations; no studies have investigated the associations of diet and CVD risk in gender minority adults. Moreover, only three of these studies used validated diet measures [7, 9, 66]. The most commonly studied CVD risk factor was obesity $(n=5)$, followed by hypertension $(n=3)$, hyperlipidemia $(n=3)$, and type 2 diabetes $(n=2)$.

In their cross-sectional online survey of 377 lesbian women (ages 18-30), Mason et al. [66] found that diet quality, measured by the Rate Your Plate simplified food frequency questionnaire, was not correlated with weight status. Diet quality scores did not differ between women of normal weight compared to women who were overweight or obese [66]. Additional studies found that dietary fat intake was not associated with higher odds of obesity, type 2 diabetes, or hypertension among sexual minority adults [7, 9]. Further, in a mixed-methods study of 40 men who have sex with men (MSM) living with HIV/AIDS, Sackey et al. [65] found no significant differences in BMI based on dietary scores. Only one study found that at least one component of diet was associated with increased obesity prevalence in sexual minority women [67]. In a convenience sample of 219 African-American lesbian and bisexual women in the U.S., Matthews and colleagues [67] found that participants who were overweight $(21.8 \%)$ and obese $(30.8 \%)$ were more likely to report consuming red meat three or more times per week compared to participants of normal weight (11.1\%). They found no differences in fruit or vegetable intake by weight status [67].

We identified only one intervention that targeted diet quality to reduce CVD and chronic disease risk in SGM adults. In a randomized controlled trial of lesbian and 
bisexual women $(N=80)$ comparing a 12-week mindfulness-based stress reduction intervention to a waitlist control group, investigators found few differences in diet between the immediate-start and waitlist control participants [68]. The intervention also included nutrition education (led by a registered dietician), physical activity, and health education and knowledge building. At the conclusion of the intervention, fruit $(p=0.10)$ nor vegetable $(p=0.17)$ intake differed between the immediate-start and waitlist groups. Notably, investigators did not report if changes in diet measures influenced CVD risk [68].

\section{Food Insecurity in SGM Adults}

The eight studies that investigated some aspects of food insecurity among SGM adults were published between 2019 and 2021 and were all conducted in the U.S. Six of these studies were cross-sectional, one study reported results of a longitudinal analysis, and one used a mixed-methods approach (Supplemental Table 1). The prevalence of food insecurity varied considerably across studies (range 10-80\%). Measures of food insecurity also varied across studies, but the U.S. Department of Agriculture's Food Security Survey Module (FSSM) was the most widely used measure $(n=3)$. Two studies did not provide sufficient detail about their measures of food insecurity. The remaining studies used non-validated measures to assess food insufficiency $(n=2)$ and food stress $(n=1)$.

\section{Sexual Minority Adults}

In one of the few studies to focus specifically on food insecurity among sexual minority women, Patterson and colleagues [69••] analyzed cross-sectional data from the NHANES (2004-2014) to determine the prevalence of household food insecurity over the past 12 months (measured using the FSSM) among sexual minority and exclusively heterosexual women. Sexual minority women had higher prevalence ratios for food insecurity and severe food insecurity compared to exclusively heterosexual women. In addition, lesbian women and heterosexual women who reported having sex with women were $89 \%$ and $43 \%$ more likely, respectively, to report use of emergency food assistance compared to exclusively heterosexual women $[69 \bullet \bullet]$.

Moreover, two studies examined aspects of food insecurity in sexual minority men, but only one of these included comparisons with heterosexual men. Using 2003-2012 data from the California Health Interview Survey [70], investigators found that among participants living in poverty, sexual minority men were less likely to be food insecure than heterosexual men $(4.6 \%$ vs. $7.6 \%, p<0.001)$. Analyses of the
Healthy Young Men's Cohort Study data found that more than one-third (36\%) of MSM reported food insufficiency in the previous 12 months (e.g., ate less or skipped meals because there was not enough money) [71].

\section{Gender Minority Adults}

Only four studies examined aspects of food insecurity among gender minority persons $[60,72,73,74 \bullet \bullet]$. In a mixedmethods study of gender minority college students $(N=26)$, Kirby and Linde [60] found that food insecurity was common in this population with $>50 \%$ of participants reporting limiting their food intake and $>30 \%$ reporting going hungry because of concerns related to food costs. Approximately $40 \%$ indicated they experienced food insecurity almost every month in the past year [60]. Also, in an online convenience sample of SGM adults $(N=253)$, investigators found that the prevalence of food insecurity (measured with the FSSM) was highest among gender minority participants [73]. Transgender male participants $(64.8 \%)$ reported a higher prevalence than gender non-binary (58.7\%), cisgender male (48.1\%), and cisgender female (46.6\%) participants. However, correlates of food insecurity were not examined [73].

Two studies found no differences in food stress and food insufficiency between gender minority and cisgender adults [72, 74••]. In analyses of data from the 2014-2015 Behavioral Risk Factor Surveillance System (BRFSS), investigators compared the prevalence of food stress between transgender $(n=261)$ and cisgender adults $(n=52,799)$ [74••]. The 2014-2015 BRFSS included a single item to measure food stress. Transgender and cisgender participants did not differ in their odds of reporting food stress (AOR 1.25, 95\% $\mathrm{CI}=0.63-2.50)$. Compared to heterosexual adults, sexual minority adults reported $49 \%$ higher odds of food insecurity,

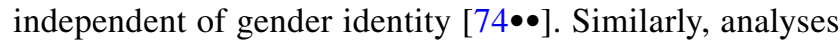
of data from the COVID-19 Resiliency Survey in Chicago $(N=201)$ found no difference in food insufficiency between transgender and cisgender participants $(10.0 \%$ vs. $10.7 \%$, $p=0.94)[72]$.

\section{Correlates of Food Insecurity in SGM Adults}

Research on correlates of food insecurity among SGM adults is limited. In the aforementioned analyses of data from the Healthy Young Men's Cohort Study, Kipke and colleagues [71] found that Black MSM (35\%) were more likely to report food insecurity than both Hispanic (21\%) and multi-racial MSM participants (22\%). In an online convenience sample of gender minority adults living in the Southeast U.S. $(N=105)$, Russomanno and Jabson Tree [75] found $\sim 80 \%$ reported food insecurity (measured using the FSSM) and $20 \%$ used local food assistance resources. Gender-related minority stressors and resilience factors were 
generally not associated with food insecurity. However, participants who reported greater transgender pride reported higher odds of using local food pantries to obtain food (AOR 1.09, 95\% CI $=1.00-1.19, p=0.04$ ) [75]. In analyses of 2014-2015 BRFSS data, investigators identified several correlates of food stress among SGM adults [74••]. Factors associated with lower odds of food stress in the full sample were increasing age, male sex, higher household income, and being retired. Factors associated with higher odds of food stress were identifying as multi-racial, being formerly married, and being unemployed [74••].

\section{Food Insecurity and CVD Risk in SGM Adults}

Although food insecurity has been associated with increased CVD risk and CVD mortality among adults [41-45], to date, no studies have examined whether food insecurity influences CVD risk in SGM adults. There are also no existing interventions focused on reducing food insecurity and related CVD risk among SGM adults.

\section{Limitations of Existing Research}

Studies that have investigated diet and food insecurity in SGM adults demonstrated significant methodological limitations and few examined their influence on CVD risk. Despite evidence that food insecurity is a predictor of poor diet quality [38, 39] and CVD risk [41-45], no study has examined these associations among SGM adults. Overall, there was inconsistent measurement of diet and food insecurity making it difficult to draw meaningful comparisons across studies. Most researchers have relied on single-item measures of diet and food insecurity, rather than validated instruments. In fact, $<40 \%$ of studies included in this review used validated instruments to assess diet and food insecurity. Most of the evidence summarized in this review was drawn from cross-sectional studies (83\%), which limits causal inference. In addition, several factors limit the generalizability of our findings. Approximately $70 \%$ of studies used convenience sampling methods to recruit SGM adults and all but one study was conducted in the U.S. Also, three out of the five studies that examined the associations of diet with CVD risk recruited SGM individuals from SGM community groups. Prior work suggests that greater SGM community connectedness is inversely associated with health concerns among SGM adults, such as depressive symptoms and sleep problems [76-78]. Participants recruited from SGM community groups may be better connected to the SGM community [65-67]. Therefore, SGM participants in the included studies may have had overall better health than SGM adults who are less connected to SGM community resources.

\section{Recommendations for Future Research}

Research on diet and food insecurity as contributors to CVD risk in SGM adults is nascent. Given the identified limitations of existing research, there is a need for future longitudinal studies that investigate the link between diet and food insecurity with CVD risk in SGM adults. We found that only five studies reported on correlates of diet and food insecurity among SGM individuals [60, 63, 64, 71, 74••]. Therefore, this review underscores the need for future studies that assess contributors to poor diet and food insecurity among SGM individuals. Intersectionality is a theoretical framework that is useful for examining how exposure to multiple forms of oppression (e.g., homophobia, sexism) influences health outcomes in minority populations $[79,80]$. Only one study in this review employed an intersectional approach to investigate differences in food insecurity [74••]. In their analyses of BRFSS data, Henderson et al. [74••] investigated whether race/ethnicity and employment status moderated the associations of gender identity with food insecurity. They found no evidence of moderation, but their analysis only included 261 gender minority participants, which may have limited their statistical power to detect moderation. Recent studies have found that Black and Hispanic SGM individuals may be at greatest risk for CVD within the SGM community $[19,81,82]$. This review supports the need for future studies that use intersectional approaches to assess whether diet and food insecurity differ among SGM adults exposed to multiple forms of oppression, such as people of color. Such research can inform public health and policy interventions that target SGM adults most at risk for poor diet and food insecurity.

\section{Recommendations for Clinical Practice}

Although the findings of this review are mixed, they have important implications for clinical practice with SGM adults. In prior qualitative research, investigators have found that traditional approaches to weight loss may be less effective and less culturally appropriate for sexual minority women [83]. Sexual minority women also report considerable variability and confusion about what is considered a healthy diet [84]. Among gay men, changes to diet intake may be more motivated by a desire to lose weight rather than eating healthily [85]. Growing evidence demonstrates that clinicians receive little education on SGM health issues and most lack adequate knowledge to care for SGM adults, particularly gender minority individuals [86-88]. Further, analyses of population-based data in the U.S. suggest that SGM adults are more likely than non-SGM adults to delay or avoid 
seeking healthcare due to concerns related to cost and other factors (e.g., transportation) $[6,89,90]$. This may place them at greater risk for undiagnosed risk factors for CVD (such as hypertension and type 2 diabetes). Tailored approaches to increase SGM individuals' engagement in healthcare and to reduce their CVD risk are needed. In particular, clinicians should be educated about important within-group social norms and attitudes related to diet among SGM individuals.

\section{Conclusions}

In this review, we summarize recent literature related to diet and food insecurity in SGM adults and their contribution to CVD risk in this population. Research investigating the associations of diet and food insecurity with CVD risk in SGM adults is nascent but has grown exponentially in the past three years. Overall, the rigor of existing studies is limited due to methodological concerns. Identified limitations in the extant literature support the need for future longitudinal studies that use validated measures to investigate the associations of diet and food insecurity with CVD risk in SGM adults. Findings highlight the need for clinicians to better understand the diet and health needs and preferences of SGM adults to promote their $\mathrm{CVH}$.

Supplementary Information The online version contains supplementary material available at https://doi.org/10.1007/s11883-022-00991-2.

Funding This work was supported by grants from the National Heart, Lung, and Blood Institute to Dr. Caceres (K01HL146965), Dr. Makarem (R00HL148511), and Dr. McClain (K01HL150406). Dr. Makarem was also supported by an American Heart Association Career Development Award (Grant \# 855050). Dr. VanKim was supported by an award from the National Institute of Diabetes, Digestive, and Kidney Disease (K01DK123193).

\section{Declarations}

Conflict of Interest The authors declare that they have no conflict of interest.

Human and Animal Rights and Informed Consent This article does not contain any studies with human or animal subjects performed by any of the authors.

\section{References}

Papers of particular interest, published recently, have been highlighted as:

- Of importance

$\bullet$ Of major importance
1. National Academy of Sciences, Engineering, and Medicine. Understanding the well-being of LGBTQI+ populations. Washington, D.C.: The National Academies Press; 2020. Available from: https://www.nap.edu/catalog/25877

2. Caceres BA, Streed CG, Corliss HL, Lloyd-Jones DM, Matthews PA, Mukherjee M, et al. Assessing and addressing cardiovascular health in LGBTQ adults: a scientific statement from the American Heart Association. Circulation. 2020;142:2747-57. https://doi.org/10.1161/CIR.0000000000000914. This scientific statement provides a summary of existing cardiovascular health research among sexual and gender minority adults.

3. Streed CG, Beach LB, Caceres BA, Dowshen NL, Moreau KL, Mukherjee M, et al. Assessing and addressing cardiovascular health in people who are transgender and gender diverse: a scientific statement from the American Heart Association. Circulation. 2021;144:e136-48. https://doi.org/10.1161/CIR. 0000000000001003 (Thisscientificstatementprovidesasummaryofexistingcardiovascularhealthresearchamonggenderminorityindividualsacrossthelifespan.).

4. Caceres BA, Brody A, Luscombe RE, Primiano JE, Marusca P, Sitts EM, et al. A systematic review of cardiovascular disease in sexual minorities. Am J Public Health. 2017; 107:e13-21. https://doi.org/10.2105/AJPH.2016.303630.

5. Liu H, Chen I-C, Wilkinson L, Pearson J, Zhang Y. Sexual orientation and diabetes during the transition to adulthood. LGBT Health. 2019;6:227-34. https://doi.org/10.1089/lgbt. 2018.0153.

6. Caceres BA, Makarem N, Hickey KT, Hughes TL. Cardiovascular disease disparities in sexual minority adults: an examination of the Behavioral Risk Factor Surveillance System (2014-2016). Am J Health Promot. 2019;33. https://doi.org/10.1177/08901 17118810246.

7. Caceres BA, Brody AA, Halkitis PN, Dorsen C, Yu G, Chyun DA. Cardiovascular disease risk in sexual minority women (18-59 years old): findings from the National Health and Nutrition Examination Survey (2001-2012). Women's Health Issues. 2018;28:333-41. https://doi.org/10.1016/j.whi.2018.03.004.

8. Kinsky S, Stall R, Hawk M, Markovic N. Risk of the metabolic syndrome in sexual minority women: results from the ESTHER Study. J Women's Health. 2016;25:784-90. https://doi.org/10. 1089/jwh.2015.5496.

9. Caceres BA, Brody AA, Halkitis PN, Dorsen C, Yu G, Chyun DA. Sexual orientation differences in modifiable risk factors for cardiovascular disease and cardiovascular disease diagnoses in men. LGBT Health. 2018;5:284-94. https://doi.org/10.1089/ lgbt.2017.0220.

10. López Castillo H, Tfirn IC, Hegarty E, Bahamon I, Lescano CM. A meta-analysis of blood pressure disparities among sexual minority men. LGBT Health. 2021;8:91-106. https://doi.org/10. 1089/lgbt.2019.0121.

11. Getahun D, Nash R, Flanders WD, Baird TC, Becerra-Culqui TA, Cromwell L, et al. Cross-sex hormones and acute cardiovascular events in transgender persons: a cohort study. Ann Int Med. 2018;169:205-13. https://doi.org/10.7326/M17-2785.

12. Caceres BA, Jackman KB, Edmondson D, Bockting WO. Assessing gender identity differences in cardiovascular disease in US adults: an analysis of data from the 2014-2017 BRFSS. J Behav Med. 2020;43:329-38. https://doi.org/10.1007/ s10865-019-00102-8.

13. Streed CG, Harfouch O, Marvel F, Blumenthal RS, Martin SS, Mukherjee M. Cardiovascular disease among transgender adults receiving hormone therapy: a narrative review. Ann Int Med. 2017;167:256-67. https://doi.org/10.7326/M17-0577.

14. Downing JM, Przedworski JM. Health of transgender adults in the U.S., 2014-2016. Am J Prev Med. 2018;55:336-344. https:// doi.org/10.1016/j.amepre.2018.04.045. 
15. Defreyne J, Van de Bruaene LDL, Rietzschel E, Van Schuylenbergh J, T'Sjoen GGR. Effects of gender-affirming hormones on lipid, metabolic, and cardiac surrogate blood markers in transgender persons. Clin Chem. 2019;65:119-34. https://doi. org/10.1373/clinchem.2018.288241.

16. Meyer IH. Prejudice, social stress, and mental health in lesbian, gay, and bisexual populations: conceptual issues and research evidence. Psychol Bull. 2003;129:674-97. https://doi.org/10. 1037/0033-2909.129.5.674.

17. Hendricks ML, Testa RJ. A conceptual framework for clinical work with transgender and gender nonconforming clients: an adaptation of the minority stress model. Prof Psychol Res Pr. 2012;43:460-7. https://doi.org/10.1037/a0029597.

18. Kcomt L, Evans-Polce RJ, Veliz PT, Boyd CJ, McCabe SE. Use of cigarettes and e-cigarettes/vaping among transgender people: results from the 2015 U.S. Transgender Survey. Am J Prev Med. 2020;59:538-47. https://doi.org/10.1016/j.amepre. 2020.03.027.

19. Caceres BA, Hughes TL, Veldhuis CB, Matthews AK. Pastyear discrimination and cigarette smoking among sexual minority women: investigating racial/ethnic and sexual identity differences. J Behav Med. 2021. https://doi.org/10.1007/ s10865-021-00217-x.

20. Poteat TC, Divsalar S, Streed CG, Feldman JL, Bockting WO, Meyer IH. Cardiovascular disease in a population-based sample of transgender and cisgender adults. Am J Prev Med. 2021;S0749379721003500. https://doi.org/10.1016/j.amepre. 2021.05.019.

21. Kidd JD, Dolezal C, Bockting WO. The relationship between tobacco use and legal document gender-marker change, hormone use, and gender-affirming surgery in a United States sample of trans-feminine and trans-masculine individuals: implications for cardiovascular health. LGBT Health. 2018;5:401-11. https://doi. org/10.1089/lgbt.2018.0103.

22. James SE, Herman JL, Rankin S, Keisling M, Mottet L, Anafi M. The report of the 2015 U.S. Transgender Survey. Washington, D.C.; 2016. Available from: https://www.transequality.org/sites/ default/files/docs/USTS-Full-Report-FINAL.PDF

23. Jones BA, Haycraft E, Bouman WP, Arcelus J. The levels and predictors of physical activity engagement within the treatmentseeking transgender population: a matched control study. J Phys Act Health. 2018;15:99-107. https://doi.org/10.1123/jpah. 2017-0298.

24. Lloyd-Jones DM, Hong Y, Labarthe D, Mozaffarian D, Appel LJ, Van Horn L, et al. Defining and setting national goals for cardiovascular health promotion and disease reduction: the American Heart Association's Strategic Impact Goal through 2020 and beyond. Circulation. 2010;121:586-613. https://doi. org/10.1161/CIRCULATIONAHA.109.192703.

25. Van Horn L, Carson JAS, Appel LJ, Burke LE, Economos C, Karmally W, et al. Recommended dietary pattern to achieve adherence to the American Heart Association/American College of Cardiology (AHA/ACC) guidelines: a scientific statement from the American Heart Association. Circulation. 2016;134:e505-29. https://doi.org/10.1161/CIR.0000000000 000462 .

26. Carson JAS, Lichtenstein AH, Anderson CAM, Appel LJ, KrisEtherton PM, Meyer KA, et al. Dietary cholesterol and cardiovascular risk: a science advisory from the American Heart Association. Circulation. 2020;141:e39-53. https://doi.org/10.1161/ CIR.0000000000000743.

27. de Oliveira Otto MC, Anderson CAM, Dearborn JL, Ferranti EP, Mozaffarian D, Rao G, et al. Dietary diversity: implications for obesity prevention in adult populations: a science advisory from the American Heart Association. Circulation. 2018;138:e160-8. https://doi.org/10.1161/CIR.0000000000000595.
28. Dai H, Much AA, Maor E, Asher E, Younis A, Xu Y, et al. Global, regional, and national burden of ischaemic heart disease and its attributable risk factors, 1990-2017: results from the Global Burden of Disease Study 2017. Eur Heart J - Qual Care Clin Outcomes. 2020. https://doi.org/10.1093/ehjqcco/qcaa076.

29. Qi X-X, Shen P. Associations of dietary protein intake with allcause, cardiovascular disease, and cancer mortality: a systematic review and meta-analysis of cohort studies. Nutr Metab Cardiovasc Dis. 2020;30:1094-105. https://doi.org/10.1016/j.numecd. 2020.03.008

30. Naghshi S, Sadeghi O, Willett WC, Esmaillzadeh A. Dietary intake of total, animal, and plant proteins and risk of all cause, cardiovascular, and cancer mortality: systematic review and dose-response meta-analysis of prospective cohort studies. BMJ. 2020. https://doi.org/10.1136/bmj.m2412.

31. Milajerdi A, Djafarian K, Shab-Bidar S. Dose-response association of dietary sodium intake with all-cause and cardiovascular mortality: a systematic review and meta-analysis of prospective studies. Public Health Nutr. 2019;22:295-306. https://doi.org/ 10.1017/S1368980018002112.

32. Li N, Wu X, Zhuang W, Xia L, Chen Y, Wang Y, et al. Green leafy vegetable and lutein intake and multiple health outcomes. Food Chem. 2021. https://doi.org/10.1016/j.foodchem.2021. 130145.

33. Wang DD, Leung CW, Li Y, Ding EL, Chiuve SE, Hu FB, et al. Trends in dietary quality among adults in the United States, 1999 through 2010. JAMA Intern Med. 2014;174:1587-95. https:// doi.org/10.1001/jamainternmed.2014.3422.

34. Rehm CD, Peñalvo JL, Afshin A, Mozaffarian D. Dietary intake among US adults, 1999-2012. JAMA. 2016;315:2542-53. https://doi.org/10.1001/jama.2016.7491.

35. Shan Z, Rehm CD, Rogers G, Ruan M, Wang DD, Hu FB, et al. Trends in dietary carbohydrate, protein, and fat intake and diet quality among US adults, 1999-2016. JAMA. 2019;322:117887. https://doi.org/10.1001/jama.2019.13771.

36. Virani SS, Alonso A, Aparicio HJ, Benjamin EJ, Bittencourt MS, Callaway CW, et al. Heart Disease and Stroke Statistics-2021 update: a report from the American Heart Association. Circulation. 2021;143:e254-743. https://doi.org/10.1161/CIR.00000 00000000950

37. Coleman-Jensen A. Household food security in the United States in 2019. United States Department of Agriculture, Economic Reserve Service; 2019.

38. Johnson CM, Sharkey JR, Lackey MJ, Adair LS, Aiello AE, Bowen SK, et al. Relationship of food insecurity to women's dietary outcomes: a systematic review. Nutr Rev. 2018;76:91028. https://doi.org/10.1093/nutrit/nuy042.

39. Hanson KL, Connor LM. Food insecurity and dietary quality in US adults and children: a systematic review. Am J Clin Nutr. 2014;100:684-92. https://doi.org/10.3945/ajen.114.084525.

40. FAO, IFAD, UNICEF, WFP, World Health Organization. The state of food security and nutrition in the world 2020: transforming food systems for affordable healthy diets. Rome, Italy; 2020. Available from: http://www.fao.org/documents/card/en/c/ca969 2en

41. Beltrán S, Pharel M, Montgomery CT, López-Hinojosa IJ, Arenas DJ, DeLisser HM. Food insecurity and hypertension: a systematic review and meta-analysis. PLoS ONE. 2020;15: e0241628. https://doi.org/10.1371/journal.pone.0241628.

42. Banerjee S, Radak T, Khubchandani J, Dunn P. Food insecurity and mortality in American adults: results from the NHANESLinked Mortality Study. Health Promot Pract. 2021;22:204-14. https://doi.org/10.1177/1524839920945927.

43. Sun Y, Liu B, Rong S, Du Y, Xu G, Snetselaar LG, et al. Food insecurity is associated with cardiovascular and all-cause 
mortality among adults in the United States. JAHA. 2020;9: e014629. https://doi.org/10.1161/JAHA.119.014629.

44. Vercammen KA, Moran AJ, McClain AC, Thorndike AN, Fulay AP, Rimm EB. Food security and 10-year cardiovascular disease risk among U.S. adults. Am J Prev Med. 2019;56:689-97. https://doi.org/10.1016/j.amepre.2018.11.016.

45. Abdurahman AA, Chaka EE, Nedjat S, Dorosty AR, Majdzadeh $R$. The association of household food insecurity with the risk of type 2 diabetes mellitus in adults: a systematic review and metaanalysis. Eur J Nutr. 2019;58:1341-50. https://doi.org/10.1007/ s00394-018-1705-2.

46. Center for American Progress and Movement Advancement Project. Paying an unfair price: the financial penalty for LGBT women in America. Washington D.C.; 2015. Available from: http://www.lgbtmap.org/policy-and-issue-analysis/ unfair-price-lgbt-women

47. Badgett MV Lee, Choi SK, Wilson BDM. LGBT poverty in the United States: a study of differences between sexual orientation and gender identity groups. 2019; Available from: https://willi amsinstitute.law.ucla.edu/wp-content/uploads/National-LGBTPoverty-Oct-2019.pdf?utm_campaign=hsric\&utm_medium= email\&utm_source=govdelivery

48. Conroy AA, Cohen MH, Frongillo EA, Tsai AC, Wilson TE, Wentz EL, et al. Food insecurity and violence in a prospective cohort of women at risk for or living with HIV in the U.S. PLoS ONE. 2019;14:e0213365. https://doi.org/10.1371/journal.pone. 0213365 .

49. Caceres BA, Markovic N, Edmondson D, Hughes TL. Sexual identity, adverse life experiences, and cardiovascular health in women. J Cardiovasc Nurs. 2019;34:380-9. https://doi.org/10. 1097/JCN.0000000000000588.

50. Blondeel K, de Vasconcelos S, García-Moreno C, Stephenson R, Temmerman M, Toskin I. Violence motivated by perception of sexual orientation and gender identity: a systematic review. Bull World Health Organ. 2018;96:29-41L. https://doi.org/10. 2471/BLT.17.197251.

51. Peitzmeier SM, Malik M, Kattari SK, Marrow E, Stephenson R, Agénor M, et al. Intimate partner violence in transgender populations: systematic review and meta-analysis of prevalence and correlates. Am J Public Health. 2020;110:e1-14. https://doi. org/10.2105/AJPH.2020.305774.

52. Dotan A, Bachner-Melman R, Dahlenburg SC. Sexual orientation and disordered eating in women: a meta-analysis. Eat Weight Disord. 2019;26:13-25. https://doi.org/10.1007/ s40519-019-00824-3.

53. Gomes SM, Jacob MCM, Rocha C, Medeiros MFA de, Lyra CO, Noro LRA. Expanding the limits of sex: a systematic review concerning food and nutrition in transgender populations. Public Health Nutr. 2021;1-44. https://doi.org/10.1017/S136898002 1001671.

54. Parker LL, Harriger JA. Eating disorders and disordered eating behaviors in the LGBT population: a review of the literature. J Eat Disord. 2020;8:51. https://doi.org/10.1186/ s40337-020-00327-y.

55. VanKim NA, Austin SB, Jun H-J, Hu FB, Corliss HL. Dietary patterns during adulthood among lesbian, bisexual, and heterosexual women in the Nurses' Health Study II. J Acad Nutr Diet. 2017;117:386-95. https://doi.org/10.1016/j.jand.2016.09.028.

56.• Solazzo AL, Arvizu M, VanKim NA, Chavarro J, Tabaac AR, Charlton BM. Variation in diet quality across sexual orientation in a cohort of U.S. women. Cancer Causes Control. 2021;32:645-51. https://doi.org/10.1007/s10552-021-01418-0. This paper is among the few analyses to use various validated measures of diet quality to examine sexual orientation differences between in diet quality.
57.•• VanKim NA, Corliss HL, Jun H-J, Calzo JP, AlAwadhi M, Austin SB. Gender expression and sexual orientation differences in diet quality and eating habits from adolescence to young adulthood. J Acad Nutr Diet. 2019;119:2028-40. https://doi.org/10. 1016/j.jand.2019.05.014. This paper reports findings from one of the few longitudinal studies that have examined gender expression and sexual orientation differences in diet quality and eating habits among young adults.

58. Laska MN, Van Kim NA, Erickson DJ, Lust K, Eisenberg ME, Rosser BRSS, et al. Disparities in weight and weight behaviors by sexual orientation in college students. Am J Public Health. 2015;105:111-21. https://doi.org/10.2105/AJPH.2014.302094.

59. Minnis AM, Catellier D, Kent C, Ethier KA, Soler RE, Heirendt W, et al. Differences in chronic disease behavioral indicators by sexual orientation and sex. J Pubic Health Manag Pract. 2016;22:S25-32. https://doi.org/10.1097/PHH.0000000000 000350 .

60. Kirby SR, Linde JA. Understanding the nutritional needs of transgender and gender-nonconforming students at a large public midwestern university. Transgender Health. 2020;5:33-41. https://doi.org/10.1089/trgh.2019.0071.

61. Madhavan M, Reddy M, Chinnakali P, Kar S, Lakshminarayanan S. High levels of non-communicable diseases risk factors among transgenders in Puducherry, South India. J Family Med Prim Care. 2020;9:1538-43. https://doi.org/10.4103/jfmpc. jfmpc_1128_19.

62. Smalley KB, Warren JC, Barefoot KN. Differences in health risk behaviors across understudied LGBT subgroups. Health Psychol. 2016;35:103-14. https://doi.org/10.1037/hea00 00231.

63. Mereish EH, Goldstein CM. Minority stress and cardiovascular disease risk among sexual minorities: mediating effects of sense of mastery. Int J Behav Med. 2020;27:726-36.

64. VanKim NA, Porta CM, Eisenberg ME, Neumark-Sztainer D, Laska MN. Lesbian, gay and bisexual college student perspectives on disparities in weight-related behaviours and body image: a qualitative analysis. J Clin Nurs. 2016;25:3676-86. https://doi. org/10.1111/jocn.13106.

65. Sackey J, Valera P, Halkitis PN, Krause KD. Exploring diet, physical activity, and body image among older men who have sex with men (MSM) who have experienced the long-term impact of HIV/AIDS. J HIV/AIDS Soc Serv. 2019;18:276-93. https://doi.org/10.1080/15381501.2019.1638334.

66. Mason TB. Binge eating and overweight and obesity among young adult lesbians. LGBT Health. 2016;3:472-6. https://doi. org/10.1089/lgbt.2015.0119.

67. Matthews AK, Li C-C, McConnell E, Aranda F, Smith C. Rates and predictors of obesity among African American sexual minority women. LGBT Health. 2016;3:275-82. https://doi. org/10.1089/lgbt.2015.0026.

68. Ingraham N, Harbatkin D, Lorvick J, Plumb M, Minnis AM. Women's Health and Mindfulness (WHAM): a randomized intervention among older lesbian/bisexual women. Health Promot Pract. 2017;18:348-57. https://doi.org/10.1177/1524839916 670874.

69.•• Patterson JG, Russomanno J, Jabson Tree JM. Sexual orientation disparities in food insecurity and food assistance use in U.S. adult women: National Health and Nutrition Examination Survey, 2005-2014. BMC Public Health. 2020;20:1155. https://doi. org/10.1186/s12889-020-09261-9. This paper is among the few analyses of population-based data to compare the 12-month food insecurity and severe food insecurity between sexual minority and heterosexual women.

70. Stupplebeen DA, Eliason MJ, LeBlanc AJ, Sanchez-Vaznaugh EV. Differential influence of weight status on chronic diseases 
by reported sexual orientation identity in men. LGBT Health. 2019;6:126-33. https://doi.org/10.1089/lgbt.2018.0167.

71. Kipke MD, Kubicek K, Akinyemi IC, Hawkins W, Belzer M, Bhandari S, et al. The Healthy Young Men's Cohort: health, stress, and risk profile of Black and Latino young men who have sex with men (YMSM). J Urban Health. 2020;97:653-67. https://doi.org/10.1007/s11524-019-00398-6.

72. Ruprecht MM, Wang X, Johnson AK, Xu J, Felt D, Ihenacho S, et al. Evidence of social and structural COVID-19 disparities by sexual orientation, gender identity, and race/ethnicity in an urban environment. J Urban Health. 2021;98:27-40. https://doi.org/10. 1007/s11524-020-00497-9.

73. Arikawa AY, Ross J, Wright L, Elmore M, Gonzalez AM, Wallace TC. Results of an online survey about food insecurity and eating disorder behaviors administered to a volunteer sample of self-described LGBTQ+ young adults aged 18 to 35 years. J Acad Nutr Diet. 2021;121:1231-41. https://doi.org/10.1016/j. jand.2020.09.032.

74.• Henderson ER, Jabson J, Russomanno J, Paglisotti T, Blosnich JR. Housing and food stress among transgender adults in the United States. Ann Epidemiol. 2019;38:42-47. https://doi.org/ $10.1016 / \mathrm{j}$.annepidem.2019.08.004. This paper is among the few analyses of population-based data to examine differences in the 12-month prevalence of food stress between gender minority and cisgender adults.

75. Russomanno J, Jabson Tree JM. Food insecurity and food pantry use among transgender and gender non-conforming people in the Southeast United States. BMC Public Health. 2020;20:590. https://doi.org/10.1186/s12889-020-08684-8.

76. Kolp H, Wilder S, Andersen C, Johnson E, Horvath S, Gidycz $\mathrm{CA}$, et al. Gender minority stress, sleep disturbance, and sexual victimization in transgender and gender nonconforming adults. J Clin Psychol. 2020;76:688-98. https://doi.org/10.1002/jclp. 22880.

77. Petruzzella A, Feinstein BA, Davila J, Lavner JA. Moderators of the association between community connectedness and internalizing symptoms among gay men. Arch Sex Behav. 2019;48:1519-28. https://doi.org/10.1007/s10508-018-1355-8.

78. Puckett JA, Matsuno E, Dyar C, Mustanski B, Newcomb ME. Mental health and resilience in transgender individuals: what type of support makes a difference? J Fam Psychol. 2019;33:954-64. https://doi.org/10.1037/fam0000561.

79. Agénor M. Future directions for incorporating intersectionality into quantitative population health research. Am J Public Health. 2020;110:803-6. https://doi.org/10.2105/AJPH.2020.305610.

80. Bauer GR. Incorporating intersectionality theory into population health research methodology: challenges and the potential to advance health equity. Soc Sci Med. 2014;110:10-7. https:// doi.org/10.1016/j.socscimed.2014.03.022.
81. Caceres BA, Veldhuis CB, Hughes TL. Racial/ethnic differences in cardiometabolic risk in a community sample of sexual minority women. Health Equity. 2019;3:350-9. https://doi.org/ 10.1089/heq.2019.0024.

82. Caceres BA, Ancheta AJ, Dorsen C, Newlin-Lew K, Edmondson D, Hughes TL. A population-based study of the intersection of sexual identity and race/ethnicity on physiological risk factors for CVD among U.S. adults (ages 18-59). Ethn Health. 2020;1-22. https://doi.org/10.1080/13557858.2020.1740174.

83. Huxley CJ, Clarke V, Halliwell E. A qualitative exploration of whether lesbian and bisexual women are "protected" from sociocultural pressure to be thin. J Health Psychol. 2014;19:273-84. https://doi.org/10.1177/1359105312468496.

84. Bowen DJ, Balsam KF, Diergaarde B, Russo M, Escamilla GM. Healthy eating, exercise, and weight: impressions of sexual minority women. Women Health. 2006;44:79-93. https://doi. org/10.1300/J013v44n01.

85. Morgan JF, Arcelus J. Body image in gay and straight men: a qualitative study. Eur Eat Disorders Rev. 2009;17:435-43. https://doi.org/10.1002/erv.955.

86. Seaborne LA, Prince RJ, Kushner DM. Sexual health education in U.S. physician assistant programs. J Sex Med. 2015;12:11581164. https://doi.org/10.1111/jsm.12879.

87. Nolan IT, Blasdel G, Dubin SN, Goetz TG, Greene RE, Morrison SD. Current state of transgender medical education in the United States and Canada: update to a scoping review. J Med Educ Curric Dev. 2020;7:238212052093481. https://doi.org/10. $1177 / 2382120520934813$.

88. Nowaskie DZ, Patel AU, Fang RC. A multicenter, multidisciplinary evaluation of 1701 healthcare professional students' LGBT cultural competency: comparisons between dental, medical, occupational therapy, pharmacy, physical therapy, physician assistant, and social work students. PLoS ONE. 2020;15: e0237670. https://doi.org/10.1371/journal.pone.0237670.

89. Dahlhamer JM, Galinsky AM, Joestl SS, Ward BW. Barriers to health care among adults identifying as sexual minorities: a US national study. Am J Public Health. 2016;106:1116-22. https:// doi.org/10.2105/AJPH.2016.303049.

90. Caceres BA, Turchioe MR, Pho A, Koleck TA, Creber RM, Bakken SB. Sexual identity and racial/ethnic differences in awareness of heart attack and stroke symptoms: findings from the National Health Interview Survey. Am J of Health Promot. 2021;35:57-67. https://doi.org/10.1177/0890117120932471.

Publisher's Note Springer Nature remains neutral with regard to jurisdictional claims in published maps and institutional affiliations. 